\title{
Photochemical Thermodynamic Efficiency Factors (PTEFs) for Hydrogen Production Using Different $\mathrm{TiO}_{2}$ Photocatalysts
}

\author{
Salvador Escobedo ${ }^{1}$, Bianca Rusinque ${ }^{1}$ and Hugo de Lasa ${ }^{1, *}$
}

Faculty of Engineering, Chemical Reactor Engineering Centre (CREC), Western University, London, ON, N6A 5B9, Canada. Email: hdelasa@eng.uwo.ca

\section{Supporting Information: Average Energy ( $\left.E_{a v}\right)$ for two Sources of light:}

\section{a) Near-UV light}

Using a spectro-photoradiometer a light spectrum was established to determine the fraction of photons (1 Einstein) emitted by near-UV lamp as shown in Figure S1, generating 1 mole of free radicals of $\mathrm{OH}^{\bullet}$ and $\mathrm{H}^{\bullet}$.

The average emitted photon energy $\left(\mathrm{E}_{\mathrm{av}}\right)$ can be calculated, once the irradiation spectrum is defined for the following relationship ${ }^{8}$,

$E_{a v}=\frac{\int_{\lambda_{\min }}^{\lambda_{\max } I(\lambda) E(\lambda) d \lambda}}{\int_{\lambda_{\min }}^{\lambda_{\max }} I(\lambda) d \lambda}$

In the case of spectra under consideration, the numerical integration of Equation (1) is restricted to the $\lambda_{\max }=410 \mathrm{~nm}$ upper wavelength. Photons with larger wavelengths do not have enough energy to supersede the $\mathrm{TiO}_{2}$ band gap and as a result to contribute to the photocatalytic transformation. Considering $E(\lambda)=h c / \lambda$ 


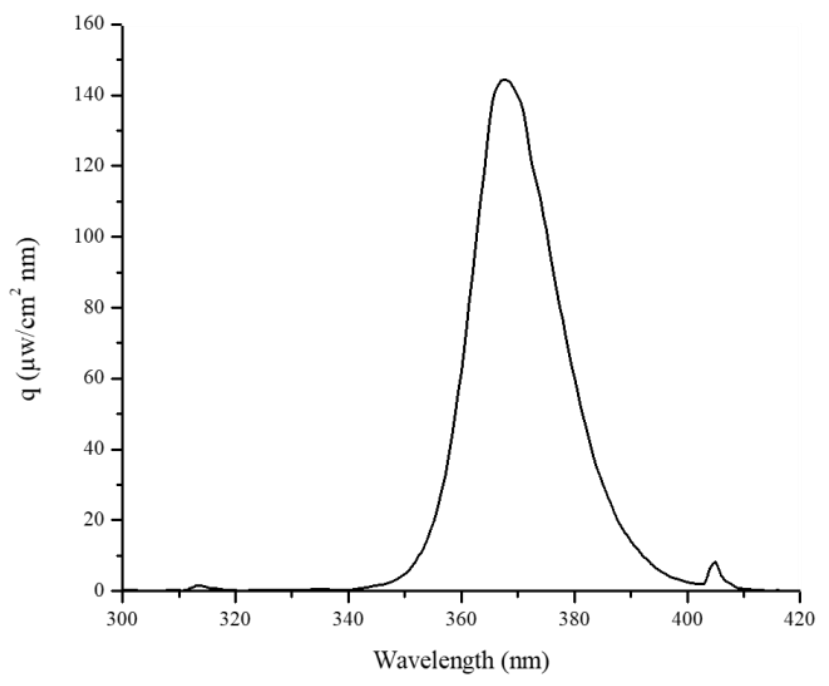

Figure S1. Near-UV light spectrum from a USHIO BLB lamp of $15 \mathrm{~W}$ of nominal input power and $4 \mathrm{~W}$ of output power.

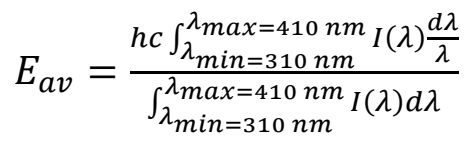

$$
\begin{gathered}
E_{a v}=\frac{\left(6.63 \times 10^{-34} \frac{\mathrm{Js}}{\text { photon }}\right)\left(3 \times 10^{8} \frac{\mathrm{m}}{\mathrm{s}}\right)}{3.69 \times 10^{-7} \mathrm{~m}}=5.38 \times 10^{-19} \frac{\mathrm{J}}{\text { photon }} \\
E_{a v}=\left(5.38 \times 10^{-19} \frac{\mathrm{J}}{\text { photon }}\right)\left(6.023 \times 10^{23} \frac{\text { photon }}{\text { mol photon }}\right)=324.1 \frac{\mathrm{KJ}}{\text { mol photon }}
\end{gathered}
$$

The Fraction of energy of two photons required to form simultaneous $\mathrm{OH}^{\bullet}$ and $\mathrm{H}^{\bullet}$ radicals, which can be calculated using Equation (3) as follows,

$$
\begin{aligned}
\eta_{\left[H^{\bullet}+\mathrm{OH}^{\bullet}\right]}=\frac{\Delta \mathrm{H}_{\left[\mathrm{H}^{\bullet}+\mathrm{OH}^{\bullet}\right]_{(l)}}^{\circ}}{E_{\text {av }}} & \\
\eta_{\left[\mathrm{H}^{\bullet}+\mathrm{OH}^{\bullet}\right]} & =\frac{503.8 \frac{\mathrm{KJ}}{\mathrm{mol}\left(\mathrm{H}^{\bullet}+\mathrm{OH}^{\bullet}\right)}}{2 \times 324.1 \frac{\mathrm{KJ}}{\text { mol photon }}}=0.77
\end{aligned}
$$




\section{b) Visible light}

Similarly as the previous analysis the average emitted photon energy $\left(\mathrm{E}_{\mathrm{av}}\right)$ for visible light, once the irradiation spectrum is defined as shown in Figure S2. In the case of spectra under consideration, the numerical integration of Equation (1) is restricted to the $\lambda_{\max }=700 \mathrm{~nm}$ upper wavelength. Photons with larger wavelengths can supersede the $\mathrm{TiO}_{2}-\mathrm{Pt}$ or Pd band gap and as a result to contribute to the photocatalytic transformation. Considering $E(\lambda)=h c / \lambda$

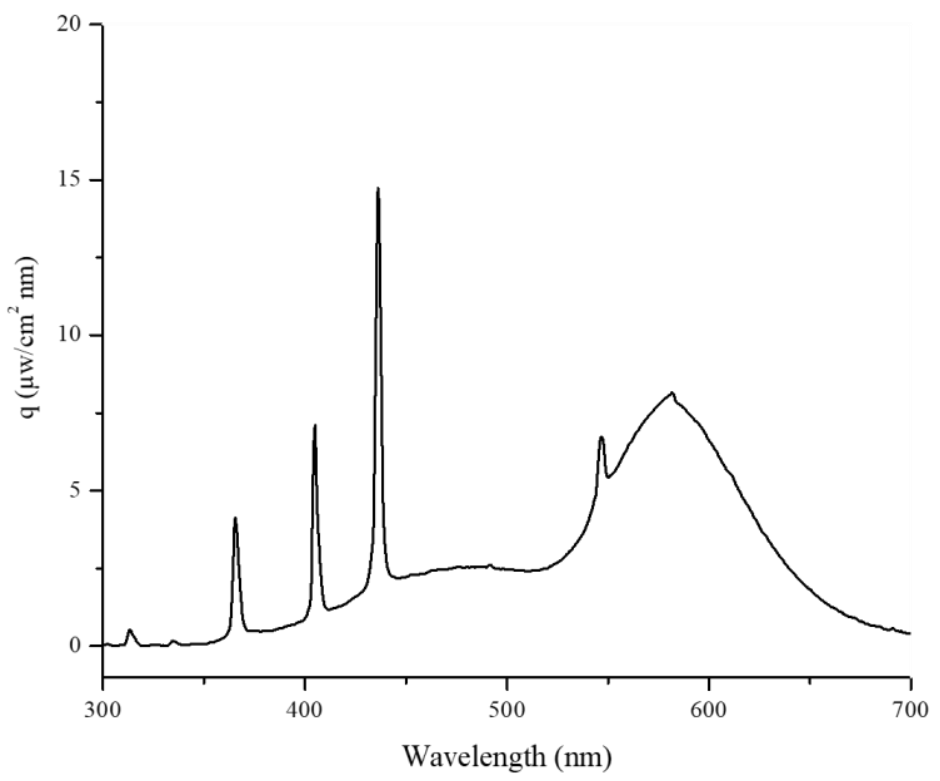

Figure S2. Visible light spectrum from a mercury Philips lamp of $15 \mathrm{~W}$ nominal input power and $1.48 \mathrm{~W}$ of output power.

$E_{a v}=\frac{h c \int_{\lambda_{\min =300 \mathrm{~nm}}}^{\lambda_{\max }=700 \mathrm{~nm}} I(\lambda) \frac{d \lambda}{\lambda}}{\int_{\lambda_{\min }=300 \mathrm{~nm}}^{\lambda_{\max }=700 \mathrm{~nm}} I(\lambda) d \lambda}$

$$
E_{a v}=274.5 \frac{K J}{\text { mol photon }}
$$

The fraction of energy of two photons required to form simultaneous $\mathrm{OH}^{\bullet}$ and $\mathrm{H}^{\bullet}$ radicals, which can be calculated using Equation (3) as follows,

$$
\eta_{\left[H^{\bullet}+\mathrm{OH}^{\bullet}\right]}=\frac{503.8 \frac{\mathrm{KJ}}{\mathrm{mol}\left(\mathrm{H}^{\bullet}+\mathrm{OH}^{\bullet}\right)}}{2 \times 274.5 \frac{\mathrm{KJ}}{\mathrm{mol} \mathrm{photon}}}=0.92
$$

